\title{
An Evaluation of Several Biochemical Markers for Bone Formation and Resorption in a Protocol Utilizing Cyclical Parathyroid Hormone and Calcitonin Therapy for Osteoporosis
}

\author{
A. B. Hodsman, ${ }^{\star}$ L. J. Fraher, ${ }^{\star}$ T. Ostbye, ${ }^{\ddagger}$ J. D. Adachi, ${ }^{\mathbf{s}}$ and B. M. Steer ${ }^{\star}$ \\ * Department of Medicine and the Lawson Research Institute, St. Joseph's Health Centre London, Ontario, Canada N6A 4V2; \\ ${ }^{\ddagger}$ Department of Epidemiology and Biostatistics, University of Western Ontario, London, Ontario, Canada N6A 5C1; and ${ }^{\S}$ St. Joseph's \\ Hospital, Hamilton, Ontario, Canada L8N 1 Y2
}

\section{Abstract}

Female patients $(n=20)$ with osteoporosis, aged $66 \pm 5$ yr were studied during a 24-h infusion of parathyroid hormone (PTH $[1-34])$ at a rate of $0.5 \mathrm{IU}$ equivalents $/ \mathrm{kg} \cdot \mathrm{h}$, and then during a 28-d period of subcutaneous injections, at a dose of 800 IU equivalents per day. Thereafter half the patients received subcutaneous injections of calcitonin, $75 \mathrm{U} / \mathrm{d}$ for $42 \mathrm{~d}$, and all patients were followed to the end of a 90-d cycle. Biochemical markers of bone formation (serum alkaline phosphatase, osteocalcin, and the carboxy-terminal extension peptide of procollagen 1 ) and bone resorption ( fasting urine calcium, hydroxyproline, and deoxypyridinoline) were compared during treatment by the intravenous and subcutaneous route of PTH administration, and subsequently during calcitonin therapy.

During intravenous PTH infusion there were significant reductions in all three bone formation markers, despite expected rises in urinary calcium and hydroxyproline. By contrast, the circulating markers of bone formation increased rapidly by $>100 \%$ of baseline values during daily PTH injections ( $P$ $<0.001)$. Significant increases in bone resorption markers were only seen at the end of the $28 \mathrm{~d}$ of injections, but were $<100 \%$ over baseline values, $(P<0.05)$. Quantitative bone histomorphometry from biopsies obtained after $28 \mathrm{~d}$ of PTH treatment confirmed that bone formation at both the cellular and tissue levels were two to five times higher than similar indices measured in a control group of biopsies from untreated osteoporotic women. Subsequent treatment of these patients with calcitonin showed no significant changes in the biochemical markers of bone formation and only a modest attenuation of bone resorption.

Thus, PTH infusion may inhibit bone formation, as judged by circulating biochemical markers, whereas daily injections confirm the potent anabolic actions of the hormone. Sequential calcitonin therapy does not appear to act synergistically with PTH in cyclical therapeutic protocols. (J. Clin. Invest. 1993. 91:1138-1148.) Key words: calcitonin • histomorphometry • osteocalcin • osteoporosis • procollagen I carboxy-terminal extension peptide $\bullet$ urinary pyridinolines

Address reprint requests to Dr. Anthony B. Hodsman, Department of Medicine, St. Joseph's Health Centre, 268 Grosvenor Street, Room 2-402, London, Ontario, Canada N6A 4V2.

Received for publication 27 April 1992 and in revised form 28 September 1992.

J. Clin. Invest.

(C) The American Society for Clinical Investigation, Inc.

$0021-9738 / 93 / 03 / 1138 / 11 \$ 2.00$

Volume 91, March 1993, 1138-1148

\section{Introduction}

Synthetic parathyroid hormone (PTH) fragments have been used as therapeutic agents to augment bone mass in osteoporotic patients since the early 1970 s (1). Most studies have utilized the hormone as an anabolic agent, giving the drug by subcutaneous daily injection for months at a time (1-4), and all have reported increases in bone mass, whether defined by bone histomorphometric or densitometric outcomes. Other investigators have used short cycles of PTH therapy for several weeks at a time (5-8). In part these alternative regimens have exploited the property of PTH to act as an activator of bone remodeling (8), utilizing repeating cycles of activation-depression treatment-free periods (ADFR). However, none of the protocols reported so far can be considered as true ADFR therapies as originally proposed by Frost (9); rather they are sequential protocols using cycles of both an activator and depressor of bone remodeling, hoping to exploit the advantages of such agents without incurring their disadvantages.

Surprisingly, there have been few attempts to evaluate the biochemical response of the osteoporotic skeleton to PTH during therapeutic trials, either in terms of circulating markers of bone formation or urinary excretion of bone resorption markers. In a preliminary evaluation of a cyclical protocol using a 14-d period of PTH therapy, followed sequentially by $56 \mathrm{~d}$ of calcitonin injections, Hodsman and Fraher (7) reported significant increases in serum alkaline phosphatase, but only small changes in serum osteocalcin (two markers of bone osteoblast activity), and concluded that the dose of PTH (1-38) used in that study ( $400 \mathrm{IU}$ equivalents per day) should be increased in future protocols using cyclical PTH therapy (7).

The anabolic effects of PTH upon bone have now been confirmed in numerous animal models (10-17). However, this presents a paradox, in that most studies of PTH action on osteoblasts in vitro suggest that this hormone is anti-anabolic. Thus continuous exposure of osteoblasts to PTH in the culture medium results in suppression of alkaline phosphatase $(18,19)$ and osteocalcin $(20,21)$ release. Tam et al. (11) first suggested that the biological actions of PTH in vivo were primarily anabolic only when the hormone was given by intermittent injection, but resorptive if given by continuous infusion. The reasons for this functional discrepancy are unknown. Clearly these differences in the pharmacological actions of PTH are crucial

1. Abbreviations used in this paper: AP, alkaline phosphatase; BMD, bone mineral density; deoxy-PYR, deoxypyridinoline; GF, glomerular filtration; i-PTH, immunoreactive PTH; MAR, mineral apposition rate; OC, osteocalcin; OH-Pro, hydroxyproline; P1CP, carboxy-terminal extension peptide of procollagen. 
to an understanding of the anabolic actions of PTH, if these are to be exploited in the future as a therapy for osteoporosis.

There are now several known biochemical markers either of osteoblast function or bone formation including serum alkaline phosphatase, osteocalcin, and the carboxy-terminal extension peptide of procollagen I (PICP). ${ }^{1}$ In addition to urinary excretion of hydroxyproline ( $\mathrm{OH}$-proline) as a marker of bone resorption, the more recently described pyridinium cross-links of collagen may be more specific and sensitive markers of bone resorption (22-24).

In this report we have evaluated this panel of bone formation and resorption markers in a group of 20 osteoporotic patients entering a clinical trial involving cycles of daily PTH injections followed sequentially by calcitonin (or placebo-calcitonin) injections. Our first objective was to compare the responses of these markers after continuous PTH infusion, with those documented after intermittent subcutaneous injections, to determine whether the different pharmacological responses observed in animals according to the route of administration are also seen in elderly humans. Our second objective was to determine whether surrogate markers of bone turnover could be used to predict responses in bone to calciotropic hormones by comparing them to changes observed in bone biopsies.

\section{Methods}

\section{Patients}

All patients recruited to this study had a clinical diagnosis of type I osteoporosis (25); primary medical problems associated with osteoporosis, including steroid therapy, adrenal or thyroid disease, and neoplastic conditions were excluded by appropriate history and biochemical tests. Radiological evidence for vertebral compression fractures was present in all subjects. All patients signed informed consent to the treatment and investigational protocol, and the study was approved by the Institutional Review Board for Research Involving Human Subjects, at the University of Western Ontario. After signing informed consent patients were randomly assigned to one of two treatment protocols, which had been modified from the experience gained in an earlier pilot study with cyclical PTH and calcitonin $(7,8)$.

Group 1. All patients received daily subcutaneous injections of hPTH (1-34) 800 IU equivalents, for $28 \mathrm{~d}$ to activate skeletal growth and remodeling.

Group 2. All patients received the same 28-d course of PTH injections, but then received a sequential daily course of subcutaneous calcitonin injections, $75 \mathrm{U}$ for $42 \mathrm{~d}$ as a depressor step.

The 20 patients reported here comprise the initial entrants into a 2-yr study protocol, designed to evaluate whether cyclical PTH, or cycles of PTH with sequential calcitonin have beneficial effects on vertebral, femoral neck, and radial bone mineral density. The study design seeks to address the need for an anti-resorptive agent in protecting cortical bone from any "catabolic" effects induced by PTH. Because of the long duration of the overall study, and the experimental nature of the hypothesis, a full factorial design (to include groups receiving only placebo or calcitonin ) was considered unacceptable by the Institutional Review Board.

Allocation of patients to the two groups was masked by treating patients in group 1 with placebo injections of calcitonin for the same 42-d period, and the code for the groups was maintained in a single dispensing pharmacy at St. Joseph's Health Centre, London, ON. All patients in groups 1 and 2 were then followed for a further 20-d treatment-free interval to complete a cycle period totaling $90 \mathrm{~d}$. At entry, all patients had a standardized 24-h infusion of hPTH (1-34) in a dose of $0.5 \mathrm{IU}$ equivalents $(8 \mathrm{pmol}) / \mathrm{kg} \cdot \mathrm{h}$ as previously described $(7)$; in addi- tion to the serum and urine biochemistry described below all patients underwent a transiliac bone biopsy on day 32 of the protocol after in vivo administration of tetracycline on days 12-14 and days 26-28. Both hPTH (1-34) [Parathar] and calcitonin [Calcimar] were supplied for the sole purpose of this study by Rhone-Poulenc-Rorer, Montreal, PQ, Canada.

It was impracticable to obtain baseline bone biopsies in the study patients before entry to the protocol. Thus the bone histomorphometry data obtained on day 32 was compared with a representative control group of 15 women enrolled into a pilot study of cyclical PTH and calcitonin therapy $(7,8)$. The inclusion and exclusion criteria for both studies were identical, as were the analytical techniques used for quantifying the bone biopsies.

\section{Methods}

Daily dietary calcium intakes were estimated for both the study patients and the control group who provided baseline histomorphometric data, using a standardized dietary questionnaire. The number of vertebral compression fractures was tabulated for both study and control groups from standardized lateral spinal $x$-rays, counting a "fracture" for any vertebra having $\geq 20 \%$ deformity in either the mid- or anterior vertebral height. Vertebral bone mineral density (BMD) was measured in all study patients at baseline, using a Hologic QDR 1000 dual-energy $\mathrm{x}$-ray densitometer (Hologic Inc., Waltham, MA), although the degree of osteopenia measured by this technique did not constitute an inclusion criterion. By way of comparison, vertebral BMD data are shown for the control group; however, these subjects were all measured $2 \mathrm{yr}$ earlier by a Lunar DP3 dual-photon densitometer (Lunar Corp., Madison, WI). Because both instruments were in one center, we are able to convert Lunar BMD data into Hologic equivalents. To establish the relationship between the two measurements, 180 osteopenic subjects referred to the metabolic bone disease clinic had vertebral BMD measurements made on the same day, but on both densitometers. As expected, a strong correlation existed between the two measurements ( $r$ $=0.96)$, described by the following equation; Hologic $\left(\mathrm{g} / \mathrm{cm}^{2}\right)=0.825$ $\times$ Lunar $\left(\mathrm{g} / \mathrm{cm}^{2}\right)-0.018$. The standard error of the estimate for the regression line was $0.045 \mathrm{~g} / \mathrm{cm}^{2}$. The relationship between the Hologic and Lunar instruments in this center is similar to that described by Gluer et al. (26). Thus the baseline BMD data for the Control patients have been converted to Hologic BMD equivalents (see Table I).

Serum samples for biochemistry were obtained at baseline on day 0 ; after 12 and $24 \mathrm{~h}$ of the PTH infusion during day 0 , and thereafter on days 14 and 28 of PTH injections, on days 40 and 70 during calcitonin / placebo injections, and at the end of the cycle on day 90 (samples obtained fasting, between 08:00 and 10:00 h, and predose). To determine the calcemic response to 800 IU equivalents of hPTH (1-34) given subcutaneously, serum calcium levels were measured pre-, $\cdot 1,4$, and $8 \mathrm{~h}$ postinjection on day 4 of PTH injections. Fasting 2-h urine samples were collected on the same days and at the same times as the serum samples. All urinary biochemical values are expressed in units of excretion per liter glomerular filtration (GF) (27).

Serum calcium ( $\mathrm{Ca}$ ), creatinine, and alkaline phosphatase (AP) were measured by standard automated methodology. Serum osteocalcin $(\mathrm{OC})$ was measured by radio immunoassay (IncStar Corp., Stillwater, $\mathrm{MN})$, with a normal reference range of $1.80-6.50 \mu \mathrm{g} /$ liter; the within and between assay coefficient of variation $(\mathrm{CV})$ was $\pm 5.3 \%$ and $4.5 \%$, respectively. Serum PICP was measured by RIA (IncStar Corp.) with a normal reference range of 64-275 $\mu \mathrm{g} /$ liter; the within and between assay $C V$ was $\pm 6.5 \%$ and $\pm 8.0 \%$, respectively. Serum immunoreactive parathyroid hormone (i-PTH) was measured by a two-site radio immunometric assay (IncStar Corp.) with a normal reference range of $0.5-5.0 \mathrm{pmol} /$ liter. There is no cross-reactivity in this assay with the (1-34) amino-terminal hormone fragment. Urinary hydroxyproline (OH-Pro) was measured by a colorimetric assay $(28)$ in fasting $2-\mathrm{h}$ urine samples after a 12-h overnight fast (thus avoiding the influence of exogenous dietary sources on OH-Pro excretion [29]), with a normal reference range of $0.90-2.30 \mu \mathrm{mol} /$ liter GF. The fasting urinary excre- 
tion of deoxypyridinoline (deoxy-PYR) was measured by a modification of the method described by Black et al. (30) with a normal reference range of $<2.57 \mathrm{pmol} /$ liter GF. Briefly $250-\mu$ l aliquots of urine were hydrolyzed with an equal volume of concentrated $\mathrm{HCl}$ at $115^{\circ} \mathrm{C}$ for $2 \mathrm{~h}$ in a domestic pressure cooker. The cross-links were extracted from the hydrolysates over cellulose ( 30 ) and then subjected to reversephase HPLC using a Nova Pak $\mathrm{C}_{18}$ column (Waters Millipore, Mississauga, ON, Canada), eluted with a gradient of $12-25 \% \mathrm{CH}_{3} \mathrm{CN}$ in water at $1 \mathrm{ml} / \mathrm{min}$ over $14 \mathrm{~min}, 10 \mathrm{mM}$ heptafluoro-butyric acid being used as an ion-pairing reagent. The column was monitored using a model M470 fluorescence detector (Waters) operating at an excitation wavelength of $295 \mathrm{~nm}$ and an emission wavelength of $390 \mathrm{~nm}$. The within and between assay $C V$ was $\pm 5.5 \%$, and $\pm 8.0 \%$ for deoxypyridinoline. Reference standards of authentic cross-links were kindly supplied by Dr. Barbara Miller of Norwich Eaton Pharmaceuticals Ltd, (Norwich, NY) and Dr. Simon Robins of the Rowett Research Institute, Aberdeen, Scotland. Fasting urinary calcium excretion was measured by atomic absorption spectrophotometry with a normal reference range of $<0.040 \mathrm{mmol} /$ liter GF. Urinary cyclic AMP (cAMP) was measured by RIA (IncStar Corp.) with a normal reference range of $<58 \mathrm{nmol} /$ liter GF. Normal reference ranges were established from a panel of 50 healthy young adults aged 20-40 yr.

To allow for comparison with previously reported data from this centre, all urinary excretion data were expressed per liter glomerular filtration (GF) using the formula: $[\mathrm{A}] \times$ [serum creatinine, $\mathrm{mmol} /$ liter]/[urinary creatinine, $\mathrm{mmol} /$ liter], where $[\mathrm{A}]$ is the urinary concentration of the analyte per liter of urine. This also has the advantage of correcting the data for natural age-related declines in GFR seen in these elderly subjects, whose creatinine clearance estimates ranged from 0.72 to $1.49 \mathrm{ml} / \mathrm{s}$ (mean $1.02 \pm 0.31$ ). Whether expressed by the more conventional referent (per millimole creatinine) or per liter of GF, the coefficients of variance of the urinary excretion data were comparable.

Trans-iliac crest bone biopsies were obtained in the 20 osteoporotic patients from this report immediately after completing the 28-d course of PTH injections. The tetracycline skeletal markers used to calculate bone formation rates were given $14 \mathrm{~d}$ apart, the first label coinciding with the midpoint of the treatment period, and the second label with the end of PTH therapy. Because it was not possible to obtain baseline bone biopsies from this group of patients, the bone histomorphometric results were compared with baseline bone biopsies obtained in 15 osteoporotic women aged $65 \pm 5 \mathrm{yr}$, who have been previously reported in an earlier clinical trial evaluating cyclical parathyroid hormone and calcitonin therapy (8). Bone histomorphometric parameters were measured as previously described (8). Quantitative histomorphometry over the cancellous surfaces was performed using the Bioquant Version 4 Software (Bioquant, Nashville, TN); the measured and derived parameters conform to the standard nomenclature and formulas recom mended by the subcommittee on bone histomorphometry of the American Society for Bone and Mineral Research (31). The static histomorphometric parameters included total bone volume per tissue volume (BV/TV, \%), osteoid volume per bone volume (OV/BV, \%) the active osteoid surface lined by cuboidal osteoblasts (ObS/OS, \%), the number of osteoblasts per unit cancellous surface (NOb/BS,cm), the total erosion surface (ES/BS, \%), the total number of osteoclasts per unit surface $(\mathrm{NOc} / \mathrm{BS}, \mathrm{cm})$. Both double and single tetracycline-labeled surfaces (dLS/BS, \%, and sLS/BS, \%) were measured to obtain the mineralizing surface (MS/BS, \%) using the correction for "label escape" (dLS + 1/2 SLS).

Dynamic parameters included the following: the mineral apposition rate (MAR, $\mu \mathrm{m} / \mathrm{d}$, unadjusted for sLS), the adjusted mineral apposition rate $(\mathrm{AjAR}, \mu \mathrm{m} / \mathrm{d})$, calculated from the formula, $M A R^{*} \mathrm{MS}$ / OS; the bone formation rate, surface referent (BFR/BS, $\mu \mathrm{m}^{3} / \mu^{2} / \mathrm{yr}$ ), calculated from the formula, MAR*MS/BS; and the activation frequency $\left(\mathrm{AcF}\right.$ per day ${ }^{-4}$ ), the probability of a remodeling event occurring along a quiescent cancelous surface. The $A c F$ was calculated from the remodeling periods at the bone multicellular unit level as $1 /[\mathrm{FP}$
+ RsP + RvP + QP], where FP is the formation period, RsP the resorption period, $\mathrm{RvP}$ the reversal period, and $\mathrm{QP}$ the quiescent period.

\section{Statistics}

All data in the text and tables are reported as mean $\pm \mathrm{SD}$, except where specifically indicated in the figures, which show standard error bars. Paired comparisons of biochemical variables within treatment groups were made using Student's $t$ tests ( using Bonferroni's correction for the number of time points sampled), except for instances where the distribution of values about the mean for the variable was not normal, in which case the nonparametric Wilcoxon's signed rank test was used. Analysis of variance (ANOVA) incorporating repeated measures for the changes in biochemical parameters between and within the two treatment groups across time was evaluated using the SAS statistical package (SAS Institute, Cary, NC). Although the subjects were randomized to the treatment groups before initiating therapy, all patients were actually treated identically for the first $28 \mathrm{~d}$. Therefore both the ANOVA as well as other statistical tests were carried out during the activation phase with daily PTH injections by contrasting the data with the baseline values (day 0 ) in all 20 patients. (As expected, the ANOVA performed separately by treatment group allocation during the first $28 \mathrm{~d}$ showed no significant differences by treatment group in any of the biochemical variables reported here.) From days 28 to 90 the ANOVA was performed in the two treatment groups, contrasting the data with the values at day 28 . By these means we could analyze separately the effects of sequential calcitonin therapy upon those changes in the biochemical markers of bone formation and resorption which had been induced by the initial activation step with PTH. Correlation coefficients were used to evaluate linear relationships between the several biochemical markers of bone remodeling at the baseline (day 0 ) and during the $28 \mathrm{~d}$ of PTH therapy. Correlation coefficients were also calculated to explore linear relationships between selected histomorphometric parameters of bone formation and resorption and the serum and urine biochemical markers measured at the time of the bone biopsy.

\section{Results}

In that it was necessary to compare the bone histomorphometric data in the study patients to an independent control group, the baseline demographic and biochemical data were carefully evaluated in both groups. This is shown in Table I. The study and control groups were not statistically different with respect to age, sex, height, weight, daily calcium intake, number of vertebral fractures, or degree of osteopenia (assessed by vertebral BMD). Within the 3 mo before entering the present study, two patients ( $10 \%)$ had been taking estrogen replacement (Premarin $0.625 \mathrm{mg}$ daily), three patients (15\%) a thiazide diuretic, seven patients ( $35 \%$ ) a calcium supplement $(<750 \mathrm{mg}$ of elemental calcium), and two patients (10\%) thyroxine replacement $(0.1 \mathrm{mg}$ of L-thyroxine daily). In contrast, the control group contained one patient $(7 \%)$ on estrogen replacement, two patients ( $13 \%$ ) on thiazides, three patients $(20 \%)$ on calcium supplements, and two patients (13\%) on thyroxine replacement. There were no differences between the two treatments' subgroups with respect to these medications.

As can be seen in Table I, there were small but statistically significant differences between some of the available baseline biochemical parameters in the two groups (for serum calcium, AP and urinary calcium excretion ); serum osteocalcin and urinary OH-Pro excretion were similar. Neither serum P1CP nor i-PTH data by a comparable assay were available for the control group. 
Table I. Demographic Data for the Current Study and for 15 Women Who Comprised the "Control" Group for the Bone Histomorphometric Data

\begin{tabular}{|c|c|c|c|}
\hline & Reference range & Study patients & Control patients \\
\hline \multicolumn{4}{|l|}{ Demographic data } \\
\hline$n$ & & 20 & 15 \\
\hline Age & & $66 \pm 5$ & $65 \pm 5$ \\
\hline Sex & & Female & Female \\
\hline Height $(\mathrm{cm})$ & & $157 \pm 6$ & $159 \pm 6$ \\
\hline Weight $(k g)$ & & $60.8 \pm 13.2$ & $60.8 \pm 8.2$ \\
\hline Dietary calcium intake $(g / d)$ & & $0.86 \pm 0.42$ & $0.96 \pm 0.24$ \\
\hline Vertebral fractures & & $3.7 \pm 2.0$ & $3.6 \pm 1.6$ \\
\hline Vertebral BMD $\left(\mathrm{g} / \mathrm{cm}^{2}\right)$ & & $0.698 \pm 0.147$ & $0.731 \pm 0.117^{\ddagger}$ \\
\hline \multicolumn{4}{|l|}{ Biochemistry } \\
\hline Serum Calcium (mmol/liter) & $2.12-2.62$ & $2.35 \pm 0.11^{*}$ & $2.24 \pm 0.08$ \\
\hline $\mathrm{AP}(I U / l i t e r)$ & $<120$ & $75 \pm 27^{*}$ & $97 \pm 22$ \\
\hline Osteocalcin $(\mu \mathrm{g} /$ liter $)$ & $1.80-6.50$ & $1.94 \pm 1.36$ & $1.98 \pm 1.22$ \\
\hline Urine OH-Pro $(\mu \mathrm{mol} /$ liter $G F)$ & $0.90-2.30$ & $2.40 \pm 1.49$ & $2.76 \pm 1.43$ \\
\hline Calcium (mmol/liter GF) & $<0.04$ & $0.027 \pm 0.013^{*}$ & $0.044 \pm 0.022$ \\
\hline
\end{tabular}

Data are mean \pm SD.

${ }^{*} P<0.05$, between the two groups.

‡ Vertebral BMD data in control group measured by dual photon densitometry and shown converted to dual energy $\mathrm{x}$-ray equivalent values (see Methods).

Table II shows the baseline characteristics for the two subgroups within the present study patients at entry (baseline). Since all patients went through an identical protocol with respect to the PTH infusion, and the first $28 \mathrm{~d}$ of PTH injections, the data in Table II are shown for the whole group of 20 patients, as well as by the two group allocations. There are no significant differences, in age, or baseline biochemical characteristics, between the two groups.

Effects of PTH infusion. During the initial PTH infusion, total serum calcium levels for all 20 patients increased from $2.35 \pm 0.11$ to $2.72 \pm 0.13 \mathrm{mmol} / \operatorname{liter}(P<0.001)$ whereas urinary cyclic AMP increased from $24.6 \pm 11.1$ to $41.1 \pm 15.5$ nmol/liter GF $(P<0.01)$. Changes in serum markers of bone formation ( $\mathrm{AP}$, osteocalcin, and P1CP) and urinary markers of bone resorption (calcium, OH-Pro, and Deoxy-PYR) across the $24 \mathrm{~h}$ PTH infusion are shown in Fig. 1. Serum AP fell progressively by a total of $9 \%$ from $75 \pm 27$ to $68 \pm 25$ IU / liter ( $P$ $<0.05)$, whereas serum osteocalcin fell by $39 \%$ from $1.94 \pm 1.36$ to $1.19 \pm 1.13 \mu \mathrm{g} /$ liter $(P<0.01)$, and serum PICP fell by $49 \%$ from $168 \pm 144$ to $86 \pm 63 \mu \mathrm{g} /$ liter $(P<0.01)$. Conversely, fasting urinary calcium excretion increased by $52 \%$ from $0.027 \pm 0.013$ to $0.041 \pm 0.034 \mathrm{mmol} / \operatorname{liter} \mathrm{GF}(P<0.02)$, urinary $\mathrm{OH}$-Pro increased by $48 \%$ from $2.40 \pm 1.49$ to $3.56 \pm 1.02 \mu /$ liter GF $(P<0.01)$. Although urinary deoxyPYR increased by $5 \%$ from $0.76 \pm 0.75$ to $0.80 \pm 0.57 \mathrm{pmol} /$ liter $\mathrm{GF}$, this difference was not significant $(P=0.50)$.

Effects of PTH and calcitonin injections. Serum calcium levels measured on the 4th d of PTH injections were as follows:

Table II. Baseline Serum and Urinary Biochemistry in the Study Patients

\begin{tabular}{|c|c|c|c|c|}
\hline & $\begin{array}{l}\text { Reference range } \\
\text { (in young adults) }\end{array}$ & All patients & $\begin{array}{l}\text { Group } 1 \\
\text { PTH only }\end{array}$ & $\begin{array}{c}\text { Group } 2 \\
\text { PTH and calcitonin }\end{array}$ \\
\hline$n$ & & 20 & 10 & 10 \\
\hline Age $(y r)$ & & $66 \pm 5$ & $67 \pm 6$ & $65 \pm 4$ \\
\hline \multicolumn{5}{|l|}{ Serum (U/liter) } \\
\hline Calcium $(\mathrm{mmol})$ & $2.12-2.62$ & $2.35 \pm 0.11$ & $2.35 \pm 0.11$ & $2.36 \pm 0.11$ \\
\hline PTH $(p m o l)$ & $0.5-5.5$ & $2.45 \pm 1.24$ & $1.99 \pm 1.19$ & $2.91 \pm 1.18$ \\
\hline $\operatorname{AP}(I U)$ & $<120$ & $75 \pm 27$ & $68 \pm 20$ & $80 \pm 31$ \\
\hline Osteocalcin $(\mu g)$ & $1.80-6.50$ & $1.94 \pm 1.36$ & $2.03 \pm 1.34$ & $1.86 \pm 1.44$ \\
\hline $\mathrm{P} 1 \mathrm{CP}(\mu g)$ & $64-275$ & $168 \pm 144$ & $145 \pm 56$ & $191 \pm 199$ \\
\hline \multicolumn{5}{|l|}{ Urine $(U /$ liter $G F)$} \\
\hline Calcium ( $\mathrm{mmol})$ & $<0.040$ & $0.027 \pm 0.013$ & $0.030 \pm 0.012$ & $0.023 \pm 0.014$ \\
\hline OH-Pro $(\mu \mathrm{mol})$ & $0.90-2.30$ & $2.40 \pm 1.49$ & $2.82 \pm 1.87$ & $1.98 \pm 0.82$ \\
\hline DYP (pmol) & $<2.57$ & $0.76 \pm 0.75$ & $0.90 \pm 0.94$ & $0.57 \pm 0.38$ \\
\hline
\end{tabular}

Data are mean \pm SD. 

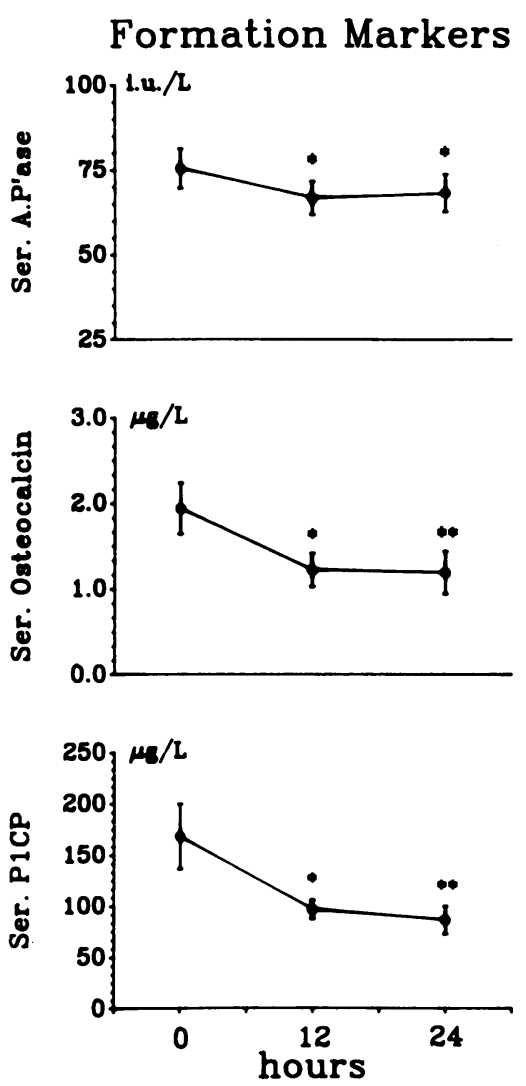
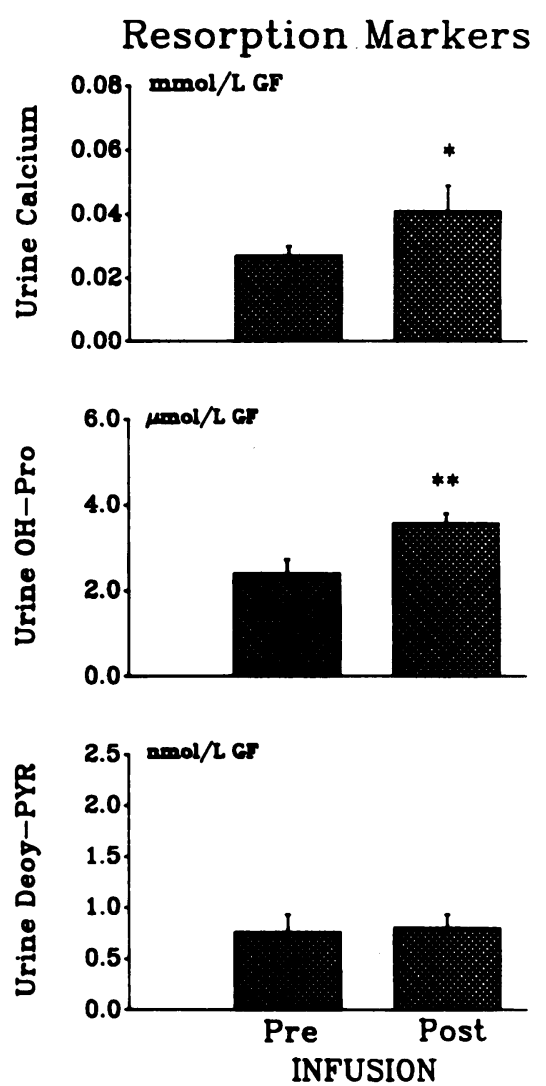

Figure 1. Biochemical markers of bone formation (left panels) and resorption (right panels) during continuous PTH infusion. The data points are mean \pm SEM $\left({ }^{*} P<0.05,{ }^{* *} P<0.01\right.$, compared to baseline).
$2.46 \pm 0.11 \mathrm{mmol} /$ liter preinjection, and $2.49 \pm 0.111 \mathrm{~h}$ postinjection, $2.57 \pm 0.10$ at $4 \mathrm{~h}$, and $2.58 \pm 0.15$ at $8 \mathrm{~h}(P<0.001$ compared to preinjection). Compared to baseline serum calcium levels before PTH therapy was started, the serum calcium levels preinjection, on day 4 , and on day 28 , were both significantly higher $(P<0.01)$, and ranged from 2.31 to $2.98 \mathrm{mmol} /$ liter. However, no symptoms accompanied the mild hypercalcemia seen in several patients.

Baseline serum i-PTH levels were $2.45 \pm 1.24 \mathrm{pmol} /$ liter, and fell to $1.27 \pm 1.35$ during PTH injections; by ANOVA this decline in endogenous i-PTH was highly significant $(P$ $\leq 0.0014$ ). Endogenous i-PTH levels were higher in the patients receiving calcitonin therapy during the rest of the cycle (group 2); the ANOVA for the period between days 28 and 90 showed a significant between group difference $(P=0.008)$, as well as a significant time interaction $(P=0.002)$; even by day 90 the serum i-PTH levels in group $2(4.63 \pm 2.19 \mathrm{pmol} /$ liter $)$ were significantly higher than those in group $1(1.83 \pm 0.96$, adjusted $P<0.05$ ). However, there were no significant differences in serum total calcium between the two groups after PTH treatment was finished, whether or not calcitonin was given (ANOVA, $P=0.79$ ).

The changes in bone formation markers for all 20 patients during the $28 \mathrm{~d}$ of PTH injections are shown in Fig. 2, together with the subsequent course according to whether the patients received placebo (group 1) or calcitonin injections (group 2). Serum AP levels increased by $104 \%$ to 154 IU / liter (adjusted $P$ $<0.001$ ), whereas serum osteocalcin increased by $259 \%$ to $6.97 \mu \mathrm{g} /$ liter (adjusted $P<0.001$ ), and P1CP increased by $140 \%$ to $404 \mu \mathrm{g} /$ liter (adjusted $P<0.001$ ). Significant increases in serum osteocalcin and P1CP (but not in alkaline phosphatase ) were seen $24 \mathrm{~h}$ after the second PTH injectiondata not shown. The maximum increases occurred by the end of the period of PTH therapy, and the mean values equaled or exceeded the upper limits of the normal reference ranges for young adults. By ANOVA, the decline in all three markers of bone formation after cessation of PTH therapy was significant across time $(P<0.001)$, but there was no significant time $X$ group interaction, and no significant overall differences were seen in the group receiving calcitonin therapy between days 28 and 70, even though calcitonin therapy in group 2 resulted in an apparently earlier decline in serum osteocalcin levels (Fig. $2)$. However, both AP and OC levels were still significantly higher than baseline by day $90(P<0.01$ adjusted for the seven time points of measurement by Bonferroni's correction.)

Fig. 3 shows the changes in urinary markers of bone resorption. All urine data are recorded from fasting 2-h collections, and expressed per liter GF. ANOVA indicated significant increases in urine calcium $(P<0.003)$ and OH-Pro $(P<0.001)$ but the increases in deoxy-PYR were not significant $(P=0.53)$ during the $28 \mathrm{~d}$ of PTH injections. By day 28 , urine calcium had increased from $0.027 \pm 0.128 \mathrm{mmol} / \mathrm{liter} \mathrm{GF}$ to $0.046 \pm 0.030$ (adjusted $P<0.04$ ), OH-Pro from $2.40 \pm 1.49$ $\mu \mathrm{mol} /$ liter GF to $3.68 \pm 1.99$ (adjusted $P<0.05$ ) and deoxyPYR from $0.76 \pm 0.75 \mathrm{pmol} /$ liter GF to $1.10 \pm 1.59$ (not significant). After discontinuing PTH therapy in group 1, there was a gradual decline in all three markers of bone resorption over time, whilst this decline was accelerated in group 2 patients who received sequential calcitonin for $42 \mathrm{~d}$. However, ANOVA showed no overall significant between-group differences from days 28 to 90 for urine calcium, and deoxy-PYR.

There was a significant within-subject time by group inter- 

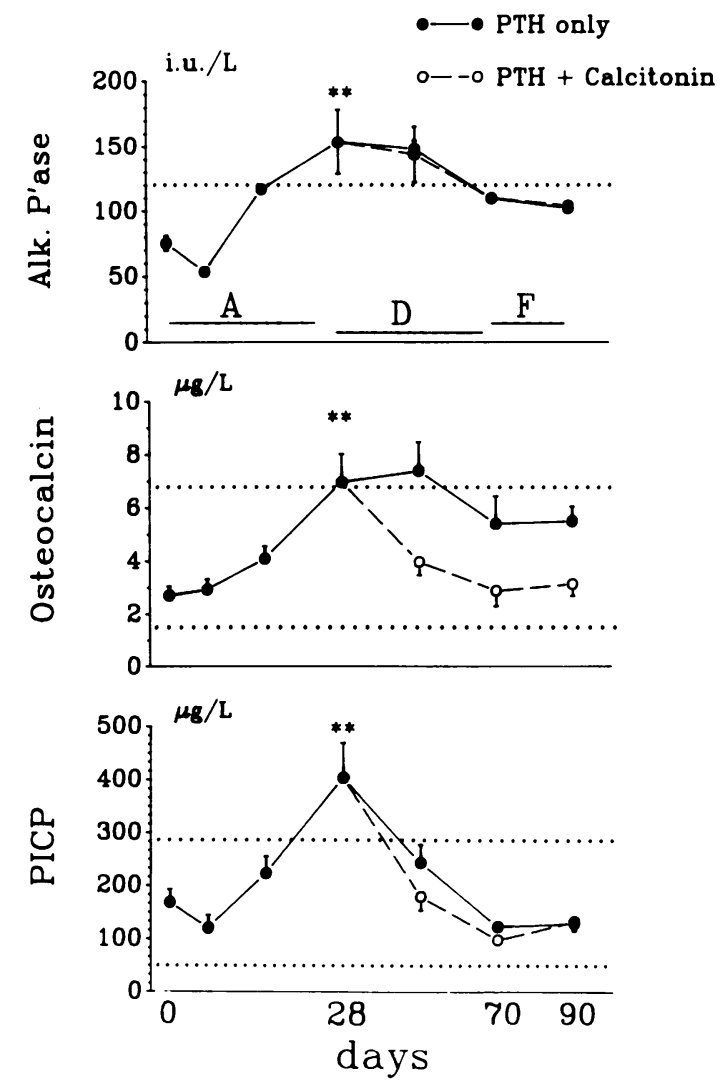

Figure 2. Serum biochemical markers of bone formation during the 90-d cycle of therapy. A = daily subcutaneous injections of PTH during the "activation" phase; $\mathrm{D}=$ daily injections of calcitonin or placebo during the "depressor" phase; $F=$ treatment-"free" period. The data are mean $\pm \mathrm{SEM}$, and the reference ranges are indicated by dotted lines $\left({ }^{* *} P<0.01\right.$ compared to pretreatment values).

action in urine $\mathrm{OH}$-Pro excretion $(P=0.027)$; post hoc analysis indicated a significantly lower OH-Pro excretion by day 42 in group 2 , during calcitonin therapy (adjusted $P<0.05$ ). However, calcitonin had no significant effects at other time points, or in either of the other urinary biochemistries.

Bone histomorphometry. Table III shows the changes in bone histomorphometric measurements for the 20 biopsies obtained at the end of PTH therapy as compared with a similar age- and sex-matched untreated group of 15 osteoporotic women. The probabilities of significant differences between the two groups are shown for unpaired Student's $t$ tests; although the variances for the data are often large, nonparametric tests did not substantially alter these conclusions, and tests of the skewness or kurtosis in the data sets indicated reasonably normal distributions. It can be seen that the total eroded surfaces (ES/BS, \%) and osteoclast counts (NOc/BS) were signifcantly increased after PTH therapy $(P<0.01)$. However, the relative osteoid volume $(\mathrm{OV} / \mathrm{BV}, \%)$ and the osteoblast counts per unit cancellous surface $\left(\mathrm{NOb} / \mathrm{BS}, \mathrm{cm}^{-1}\right.$ ) were also significantly increased $(P \leq 0.002)$; the double-labeled tetracycline surfaces ( $\mathrm{dLS} / \mathrm{BS}, \%)$ and the overall mineralizing surfaces (MS/BS, \%) were increased over twofold $(P<0.005)$ compared to the untreated controls, although there were no differences in either the MAR or adjusted apposition rate ( $\mathrm{AjAR}$ ). Because $(a)$ the increases in mineralizing surfaces are largely
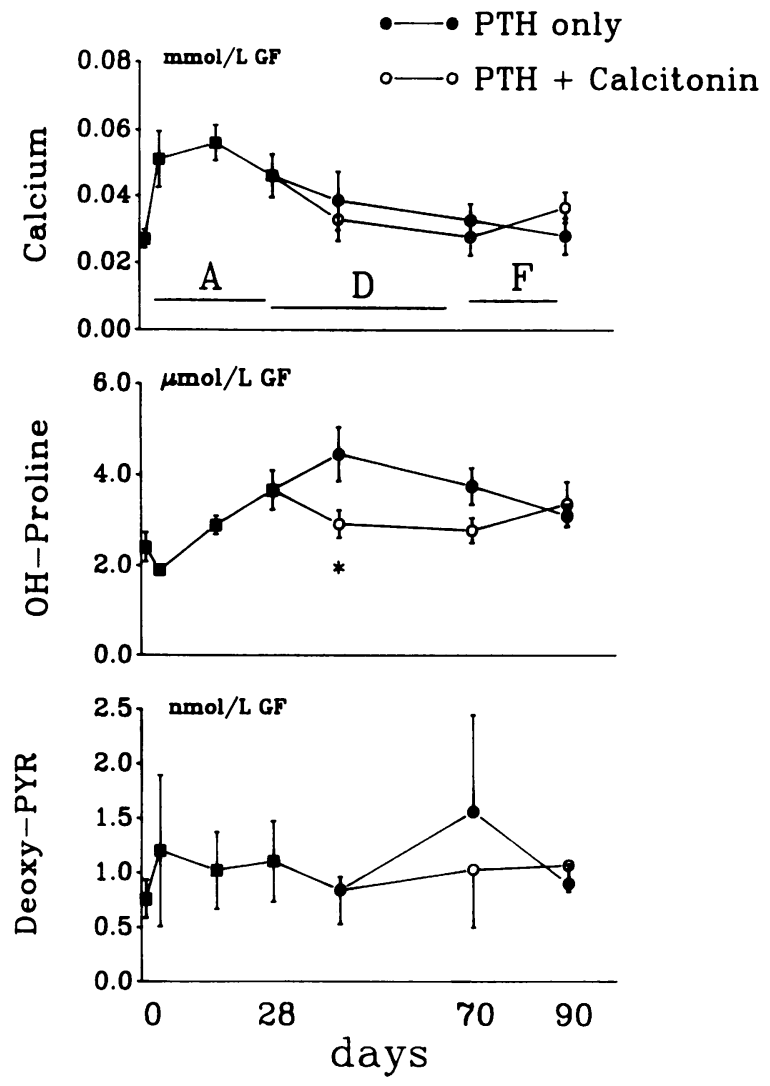

Figure 3. Urinary biochemical markers of bone resorption during the 90-d cycle of therapy. A = daily subcutaneous injections of PTH during the "activation" phase; $\mathrm{D}=$ daily injections of calcitonin or placebo during the "depressor" phase; $\mathrm{F}=$ treatment-"free" period. . The data are mean \pm SEM $\left({ }^{*} P<0.01\right.$, compared to placebo at this time point).

accounted for by increases in double-labeled surfaces, and $(b)$ the first tetracycline label was given after only $14 \mathrm{~d}$ of PTH therapy, it is possible that the increased bone formation is occurring on previously quiescent bone surfaces, rather than as a "coupled" consequence of a completed resorption cycle-i.e., bone resorption and formation are uncoupled and occurring concurrently. The bone formation rates (BFR/BS) were significantly increased during PTH therapy $(P<0.03)$. Using the calculations for the components of the remodeling cycle (which assumes that bone remodeling is a coupled process of bone resorption and formation ), the activation frequency increased by 2.5 -fold during the $28 \mathrm{~d}$ of PTH therapy $(P<0.02)$.

Correlation coefficients were calculated between the biochemical markers and selected bone histomorphometric parameters in the current study. Before PTH therapy, (i.e., at baseline) there was a significant correlation between serum AP and OC ( $r=0.57, P<0.01)$, but not with P1CP. However, when all serum measurements of bone formation markers were included during the $28 \mathrm{~d}$ of PTH therapy (Table IV A), the correlations between $\mathrm{OC}$ and AP remained significant although there was a weaker correlation between PICP and AP. Urine OH-Pro excretion correlated significantly with fasting urine calcium both before treatment $(r=0.50, P<0.05)$ and throughout the period of PTH therapy (Table IV A). There were no significant correlations with urine deoxy-PYR. 
Table III. Bone Histomorphometric Variables in Study Patients after 28 d of PTH Injections, Compared with an Age-matched Control Group of Osteoporotic Women

\begin{tabular}{lcccc}
\hline & Reference values & $\begin{array}{c}\text { Control } \\
(n=15)\end{array}$ & $\begin{array}{c}\text { Study } \\
(n=20)\end{array}$ & $P$ value \\
\hline BV/TV, $\%$ & $22.0 \pm 7.3^{*}$ & $21.2 \pm 8.8$ & $19.3 \pm 8.1$ & NS \\
ES/BS, $\%$ & $2.9 \pm 1.0^{*}$ & $4.9 \pm 2.9$ & $13.1 \pm 5.4$ & 0.001 \\
NOc/BS, $c m^{-1}$ & $7.5 \pm 4.8^{\ddagger}$ & $1.3 \pm 1.9$ & $4.7 \pm 4.4$ & 0.006 \\
OV/BV, \% & $3.0 \pm 1.3^{*}$ & $1.2 \pm 0.7$ & $3.4 \pm 1.7$ & 0.001 \\
O.Th, $\mu m$ & $8.5 \pm 1.9^{*}$ & $5.0 \pm 1.4$ & $6.0 \pm 1.2$ & 0.03 \\
ObS/OS, $\%$ & & $14.9 \pm 12.1$ & $25.9 \pm 20.7$ & 0.06 \\
NOb/BS, $c m^{-1}$ & N/A & $5.9 \pm 7.6$ & $28.4 \pm 26.0$ & 0.002 \\
SLS/BS, $\%$ & $2.5 \pm 2.0^{*}$ & $6.2 \pm 4.2$ & $10.1 \pm 7.6$ & 0.07 \\
dLS/BS, $\%$ & $4.4 \pm 3.8^{*}$ & $3.9 \pm 3.2$ & $11.0 \pm 9.1$ & 0.005 \\
MS/BS, $\%$ & $5.6 \pm 4.0$ & $7.0 \pm 4.0$ & $16.0 \pm 12.0$ & 0.005 \\
MAR, $\mu m d^{-1}$ & $0.53 \pm 0.06^{*}$ & $0.40 \pm 0.13$ & $0.46 \pm 0.17$ & NS \\
Aj.Ar, $\mu m d^{-1}$ & $0.11 \pm 0.13^{*}$ & $0.27 \pm 0.09$ & $0.25 \pm 0.15$ & NS \\
BFR/BS $\mu m^{3} / \mu m^{2} p e r y r$ & $11.0 \pm 7.7^{*}$ & $11 \pm 7$ & $31 \pm 35$ & 0.03 \\
AcF, $/ d \times 10^{-4}$ & $10 \pm 4^{\ddagger}$ & $15 \pm 7$ & $38 \pm 37$ & 0.02 \\
\hline
\end{tabular}

Data are mean \pm SD.

${ }^{*}$ Dahl et al. (53); ${ }^{\ddagger}$ Eriksen et al. (54).

There were significant correlations between serum osteocalcin levels measured on day 28 and several histomorphometric parameters of mineralisation and bone formation ( Table IV B), but fewer correlations with serum P1CP, and no correlations with serum AP. Only urine OH-Pro excretion correlated with the histologic measurement of surface osteoclast counts. No correlations were seen with any histologic measurement of bone resorption and either urine calcium or deoxy-PYR.

\section{Discussion}

The evaluation of the biochemical changes in serum and urinary markers of bone turnover supported the initial hypothesis that continuous intravenous infusion of PTH (1-34) might act to depress bone formation. Conversely intermittent daily subcutaneous injections of this hormone resulted in a markedly anabolic action, confirmed by both biochemical and histologi-

Table IV. Correlation Coefficients (r) between Biochemical Markers (A) and Bone Histomorphometric Parameters (B)

\begin{tabular}{|c|c|c|c|c|c|c|c|c|c|}
\hline \multirow[t]{2}{*}{ A. } & \multicolumn{3}{|c|}{ Bone formation markers } & & \multicolumn{4}{|c|}{ Bone resorption markers } & \\
\hline & Serum & AP & $\mathrm{OC}$ & & & Urine & $\mathrm{Ca}$ & OH-Pro & \\
\hline SERUM & & & & & URINE & & & & \\
\hline Osteocalcin & & $0.49^{\ddagger}$ & & & OH-Pro & & $0.39^{*}$ & & \\
\hline PICP & & $0.37^{\ddagger}$ & 0.25 & & Deoxy-PYR & & -0.08 & -0.02 & \\
\hline \multirow[t]{2}{*}{ B. } & \multicolumn{3}{|c|}{ Formation } & & \multicolumn{5}{|c|}{ Resorption } \\
\hline & Serum & A'Pase & Osteocalcin & P1CP & & Urine & $\mathrm{Ca}$ & OH-Pro & Deoxy-PYR \\
\hline BONE & & & & & BONE & & & & \\
\hline $\mathrm{OTh}$ & & 0.06 & 0.05 & 0.15 & ES/BS & & 0.27 & 0.36 & 0.12 \\
\hline OV/BV & & 0.24 & $0.39^{*}$ & $0.47^{*}$ & NOc/BS & & 0.10 & $0.50^{*}$ & 0.15 \\
\hline $\mathrm{NOb} / \mathrm{BS}$ & & 0.07 & 0.33 & 0.19 & & & & & \\
\hline sLS/BS & & 0.14 & 0.35 & 0.25 & & & & & \\
\hline dLS/BS & & 0.04 & $0.51^{*}$ & $0.43^{*}$ & & & & & \\
\hline MS/BS & & 0.07 & $0.49^{*}$ & $0.40^{*}$ & & & & & \\
\hline MAR & & 0.15 & 0.25 & 0.00 & & & & & \\
\hline $\mathrm{BFR} / \mathrm{BS}$ & & 0.16 & $0.65^{\ddagger}$ & 0.28 & & & & & \\
\hline $\mathrm{AcF}$ & & 0.13 & $0.68^{\ddagger}$ & 0.28 & & & & & \\
\hline
\end{tabular}

A. Correlations made for all time points, day 0-28.

B. Biochemical markers on day 28 correlated with bone histomorphometry.

${ }^{*} P<0.05,{ }^{\ddagger} P<0.01$. 
cal evidence. Both routes of hormone delivery led to increased bone resorption. Compared to the changes in biochemical markers of bone turnover seen after PTH (1-34) therapy, calcitonin had a limited impact on selected markers of bone resorption, suggesting that this hormone will have a minimal synergistic role to play in the development of combined anabolic/ antiresorptive protocols of osteoporosis therapy.

When exposed to PTH in tissue culture, osteoblast-like cells typically respond by a reduced secretion of both $\operatorname{AP}(18,19,32$, $33)$ and $O C(20,21)$, suggesting that PTH inhibits matrix synthesis. In this study, continuous intravenous infusion of PTH (1-34) also led to significantly reduced circulating levels of AP, $\mathrm{OC}$, and P1CP. This confirms our earlier finding that both PTH (1-34) and PTH-related peptide infusion in young healthy subjects resulted in reduced circulating osteocalcin levels (34) and that of Riggs et al. (35), who also found reduced serum osteocalcin levels after infusion of PTH (1-34) in young normal controls.

OC levels exhibit a diurnal variation with peak serum concentrations occurring in the late afternoon and a nadir in midmorning (36). It is unlikely that the fall in serum osteocalcin levels seen after $12 \mathrm{~h}$ of infusion were attributable to diurnal variation in that such a fall was asynchronous with the anticipated peak in diurnal levels, while the 24-h nadir was significantly lower than the baseline obtained at the same time on the previous day. We advanced similar arguments about the effects of both PTH and parathyroid hormone-related peptide infusion in young healthy adults (34). It is equally unlikely that diurnal variations in serum $\mathrm{AP}$ and $\mathrm{P} 1 \mathrm{CP}$ explain the observed responses during PTH infusion. However this question can only be resolved definitively by observing the changes in these parameters in age- and sex-matched osteoporotic patients infused with vehicle alone; this was not an option we were able to pursue in this study protocol.

These findings are consistent with the conclusion that continuous exposure to PTH leads to suppression of osteoblast matrix synthesis. However other explanations are valid, including the possibility that continuously high levels of PTH alter osteoblast release of these proteins to the extracellular fluid, or selectively modify the synthesis of some intracellular proteins without impacting on osteoid matrix production.

It is most unlikely that experimental histological confirmation of this anti-anabolic action of PTH will ever be available in humans. Nonetheless histological studies after continuous PTH infusion in both dogs $(37,38)$ and rats (11) clearly show that the effects are primarily of increased bone resorption or increased activation frequency of remodeling, with no evidence for increased bone formation. The natural experiment in humans subjected to continuously increased levels of PTH is represented by primary hyperparathyroidism. However, this state is clearly different from that of exogenous infusion, because patients with endogenous hyperparathyroidism frequently have increased circulating markers of bone formation including AP and OC $(39,40)$, and bone biopsies usually demonstrate evidence of increased bone formation $(41,42)$. Thus patients with primary hyperparathyroidism have more similarities to the findings in subjects given intermittent PTH injections, as discussed below.

During the $28 \mathrm{~d}$ of subcutaneous PTH injections, there were striking increases in serum AP (by $104 \%$ of baseline), OC (259\%) and P1CP (140\%), to levels that clearly exceed the upper limits of the normal ranges for these markers. The responses in bone formation markers appear to be dose dependent. In a pilot study of a cyclical protocol using half the dose and duration of PTH injections, Hodsman et al. (7) reported increases in AP and OC of only $25 \%$ and $72 \%$, respectively. In another cyclical treatment protocol, utilizing 400 IU equivalents PTH ( 1-38) daily for $70 \mathrm{~d}$ at a time, Hesch et al. (5) found a progressive increase in AP of $40 \%$ during the first year, whereas Reeve et al. (2) reported only a $15 \%$ increase using continuous daily dosing of $500 \mathrm{IU}$ equivalents PTH (1-34). These changes may represent increased bone matrix synthesis and mineralization in the skeleton.

In a recent consensus development conference on osteoporosis, the value of serum and urinary markers of bone formation and resorption was discussed. In particular, serum $O C$ appeared to be the most sensitive marker of bone turnover when bone formation and resorption are coupled, and of bone formation whenever bone formation and resorption are uncoupled (as may well be the case in the present study) (43). Serum levels of AP and P1CP appear to provide similar information $(43,44)$. Direct confirmation of this can be inferred from the bone biopsies obtained at the end of the period of PTH injections. Thus the osteoid volume (OV/BV), active osteoid surfaces, (ObS/OS and NOb/BS), double-labeled tetracycline surface ( $\mathrm{dLS} / \mathrm{BS}$ ), and bone formation rates (BFR/ BS) were two- to fivefold increased over those obtained in control biopsies in osteoporotic women (Table III).

It is difficult to compare the histomorphometric findings in these biopsies with previously published data. Few authors have attempted to quantitate very early changes in response to PTH therapy. Hodsman et al. (8) showed an insignificant increase $(17 \%)$ in BFR/BS after two 3-mo cycles of sequential PTH/calcitonin therapy, but the activation frequency increased significantly by twofold, which is similar to the high remodeling activation frequency observed in the current study. However, this earlier study used only $25 \%$ of the cumulative doses of PTH in each treatment cycle. The dynamic histomorphometric data of Reeve et al. (2), obtained from iliac biopsies in PTH-treated patients after 6-24 mo of daily injections are unfortunately not comparable to the data reported here due to differences in histomorphometric techniques. However, it would appear that the patients reported by Reeve et al. (2) received 500 U PTH (1-34) daily and increased osteoid forming surfaces by $\sim 50 \%$ over the long term (2). All other reported studies of the anabolic effects of PTH have utilized longterm changes in BMD as the outcome measurement, and are therefore not comparable to the data reported here.

It was not possible to evaluate bone histomorphometric data in this study against an internal control, with each patient serving as her own control (by having a pretreatment bone biopsy). It was therefore necessary to compare histologic findings against an independent control group. As can be seen in Table I, the demographic data between the two groups of subjects suggest they were indeed well matched clinically. Indeed the inclusion and exclusion criteria for entry into both studies (the pilot study and current study) were identical. However there were significant baseline differences in serum biochemistry between the two groups. Thus the control group had significantly lower serum calcium, higher serum AP, and higher urinary calcium excretion levels than the current study group. Since fewer individuals within the control group were taking 
calcium supplements on entry to the pilot study, some of these findings might be explained by higher endogenous PTH secretion in the control group. Unfortunately changes in the i-PTH assay methodology between the two groups do not allow this hypothesis to be tested. However, it should be stressed that if the control group did have relatively higher endogenous i-PTH levels, the bone histomorphometric data would have been biased against finding significant differences between the two groups of bone biopsies. Despite this potential bias, the levels of significance between the two groups are so consistent that it is difficult to ascribe another explanation for the differences other than the effects of exogenous PTH therapy.

Of the three formation markers, serum osteocalcin demonstrated the largest responses to PTH therapy, and correlated significantly with serum AP $(r=0.49)$ but not with P1CP $(r$ $=0.25$ ) and with several histological markers of bone formation, including the derived calculation of bone formation rate (Table IV, BFR/BS; $r=0.65$ ) and activation frequency (AcF; $r=0.68)$. Thus OC may be the marker of choice to monitor changes in skeletal metabolism in osteoporosis. Even in untreated older women, serum osteocalcin levels have been found to correlate with histologic indexes of bone formation rate (45), whereas increases in OC in response to fluoride therapy are more consistent than changes in AP (46). The changes in serum P1CP were intermediate between those of OC and AP. This carboxy-terminal extension peptide is released into the circulation during synthesis of type I collagen, the dominant collagen species in bone. Although it has the theoretical advantage of reflecting de novo skeletal synthesis of collagen matrix, the overall correlations between P1CP and bone histomorphometric variables in this study were not as pronounced as those for osteocalcin (Table III). Similarly, where direct comparisons of changes in serum $\mathrm{P} 1 \mathrm{CP}$, and $\mathrm{OC}$ or $\mathrm{AP}$ have been made in circumstances where bone turnover was abruptly reduced by antiresorption therapy, the changes in P1CP levels mirrored those of the other two markers $(44,47-49)$. Whether measurement of P1CP levels provides any predictive information not obtained by measuring osteocalcin levels remains to be seen.

The changes in bone resorption markers were monitored in fasting urines, including calcium, OH-Pro, and deoxy-PYR excretion. By choosing the fasting state and expressing the data per liter of GFR, we attempted to correct for dietary influences and differences in renal function, but may have missed more integrated responses of the skeleton over $24 \mathrm{~h}$. The most consistent statistical changes were observed in urinary $\mathrm{OH}$-Pro excretion which increased progressively during the period of PTH injections and correlated significantly with the surface osteoclast counts in the final bone biopsy data ( NOc/BS, $r=0.50$ ). However the $53 \%$ increase in urine $\mathrm{OH}$-Pro is clearly less pronounced than the percentage increases in bone formation markers, suggesting that bone formation is the dominant response to intermittent PTH therapy. The increases in histological parameters of bone resorption and the gradual increase in urine $\mathrm{OH}$-Pro excretion are consistent with the progressive recruitment of new bone multicellular units (BMUs) as bone remodeling is activated by PTH. Indeed, using the classical BMU-based derivational formulae for calculating the activation frequency of bone remodeling over previously quiescent surfaces, the bone biopsy data demonstrated a twofold increase in activation frequency over the control group of biopsies. However some caution is needed to interpret the activation fre- quency calculation, which assumes that bone formation is coupled in time and space to a preexisting resorption site. In this series of biopsies, it is difficult to envision that the two- to threefold increase in double-tetracycline labels (representing bone formation ) is a consequence of coupled bone resorptionformation, as is predicted by current concepts of bone remodeling. The first tetracycline label was given after only $14 \mathrm{~d}$ of PTH therapy, before any significant increase in hydroxy-prolinuria (see Fig. 3). If the increase in bone forming surfaces had been coupled to preexisting resorption sites, then the time frame of recruitment for both osteoclasts and osteoblasts must have been very truncated. The biochemical time course of the putative markers for bone formation and resorption are consistent with the cellular events occurring in bone in an uncoupled fashion (i.e., both events might be occurring on previously quiescent surfaces). Nonetheless we postulate this hypothesis with considerable caution since the relative magnitudes of the histomorphometric changes are being compared with an independent group of control biopsies, which were not obtained from a patient population who were randomly assigned within the current study.

The changes in deoxy-PYR excretion were not striking. Deoxy-PYR is a cross-linked lysylpyridinoline which is released during collagen degradation and is relatively specific of the break-down of bone collagen $(22,50)$. There is evidence that 24-h excretion of deoxy-PYR is more sensitive than $\mathrm{OH}$ Pro as a marker of bone turnover in both normal and abnormal bone metabolism (22-24). That we could not confirm the utility of deoxy-PYR as a better marker of bone resorption than $\mathrm{OH}$-Pro may have been due to the choice of fasting urine samples, rather than a full 24-h urine collection. However, previous reports have suggested that fasting urinary deoxy-PYR measurements have proven to be significant predictors of bone turnover and resorption $(51,52)$. Finally, we assessed the impact of sequential calcitonin therapy on the biochemical markers of bone turnover. As can be seen in Fig. 2, calcitonin did not affect the course of the bone formation markers which gradually declined toward baseline once PTH therapy was stopped; the apparent attenuation of the serum osteocalcin response was not significant. There was a modest attenuation in the bone resorption markers during calcitonin therapy, which was significant only for OH-Pro excretion (Fig. 3). Similar results were reported in our earlier report of a PTH/calcitonin protocol (7). We conclude from these two studies that the addition of calcitonin appears to confer no obvious advantages as assessed by biochemical responses reflecting skeletal turnover. Indeed the potent effects of PTH as both an anabolic and activation agent may make therapy with this hormone relatively feasible if it can be given alone for several short cyclical courses a year rather than by continuous daily injections. The present study is designed to follow bone mineral density responses over eight such cycles in an expanded trial which should provide a more definitive outcome to this question.

In conclusion, we have reported the biochemical responses to both continuously infused, and intermittently injected PTH (1-34); although PTH appears to be anti-anabolic when administered by infusion, it has strongly anabolic actions when given by intermittent injections. Serum osteocalcin levels and urine $\mathrm{OH}$-Pro excretion appeared to be the most sensitive respective biochemical markers of bone formation and resorption. Bone histomorphometric studies at the end of the 28-d 
period of PTH (1-34) injections suggested that PTH was indeed a potent activator of bone remodeling but, in addition, resulted in osteoid matrix synthesis which may have occurred de novo on quiescent cancellous bone surfaces.

\section{Acknowledgments}

Mr. L. Stitt, Biostatistical Support Unit, University of Western Ontario, assisted with data analysis. We wish to thank Ms. Laurie Clark for her help with preparing the manuscript. Ms. F. O'Brien and Ms. L. Froste supervised the nursing care of our patients throughout the protocol; without their help this study could not have been performed.

The authors acknowledge the support of the Medical Research Council of Canada and the sponsorship of these studies by the RhonePoulenc-Rorer Pharmaceutical Company through both the Canadian (Montreal, PQ) and USA (Horsham, PA) divisions in two separate operating grants.

\section{References}

1. Reeve, J., R. Hesp, D. Williams, L. Klenerman, J. M. Zanelli, A. J. Darby, G. W. Tregear, J. A. Parsons, and R. Hume. 1976. Anabolic effect of low doses of a fragment of human parathyroid hormone on the skeleton in postmenopausal osteoporosis. Lancet. i:1035-1038.

2. Reeve, J., P. J. Meunier, J. A. Parsons, M. Bernat, O. L. M. Bijvoet, P. Courpron, C. Edouard, L. Klenerman, R. M. Neer, J. C. Renier, et al. 1980. Anabolic effect of human parathyroid hormone fragment on trabecular bone in involutional osteoporosis: a multicentre trial. Br. Med. J. 1340-1344.

3. Slovik, D. M., D. I. Rosenthal, S. Doppelt, J. T. Jr. Potts, M. A. Daly, J. A. Campbell, and R. M. Neer. 1986. Restoration of spinal bone in osteoporotic men by treatment with human parathyroid hormone (1-34) and 1,25-dihydroxyvitamin D. J. Bone Miner. Res. 1:377-381.

4. Reeve, J., U. M. Davies, R. Hesp, E. McNally, and D. Katz. 1990. Treatment of osteoporosis with human parathyroid peptide and observations on the effect of sodium fluoride. Br. Med. J. 301:314-318.

5. Hesch, R. D., U. Busch, M. Prokop, G. Delling, and E. F. Rittinghaus. 1989. Increase of vertebral density by combination therapy with pulsatile 1-38 $\mathrm{hPTH}$ and sequential addition of calcitonin nasal spray in osteoporotic patients. Calcif. Tissue Int. 44:176-180.

6. Reeve, J., M. Arlot, T. R. Price, C. Edouard, R. Hesp, P. Hulme, J. P. Ashley, J. M. Zanelli, J. R. Green, M. Tellez, et al. 1987. Periodic courses of human 1-34 parathyroid peptide alternating with calcitriol paradoxically reduce bone remodeling in spinal osteoporosis. Eur. J. Clin. Invest. 17:421-428.

7. Hodsman, A. B., and L. J. Fraher. 1990. Biochemical responses to sequential human parathyroid hormone $(1-38)$ and calcitonin in osteoporotic patients. Bone. Miner. 9:137-152.

8. Hodsman, A. B., B. M. Steer, L. J. Fraher, and D. J. Drost. 1991. Bone densitometric and histomorphometric responses to sequential human parathyroid hormone (1-38) and salmon calcitonin in osteoporotic patients. Bone Miner. 14:67-83.

9. Frost, H. M. 1981. Coherence treatment of osteoporosis. Orthop. Clin. N. Am. 12:649-669.

10. Podbesek, R., C. Edouard, P. J. Meunier, J. A. Parsons, J. Reeve, R. W. Stevenson, and J. M. Zanelli. 1983. Effects of two treatment regimens with synthetic human parathyroid hormone fragment on bone formation and the tissue balance of trabecular bone in greyhounds. Endocrinology. 112:1000-1006.

11. Tam, C. S., J. N. M. Heersche, T. M. Murray, and J. A. Parsons. 1982. Parathyroid hormone stimulates the bone apposition rate independently of its resorptive action; differential effects of intermittant and continuous administration. Endocrinology. 110:506-512.

12. Hori, M., T. Uzawa, K. Morita, T. Noda, H. Takahashi, and J. Inoue. 1988. Effect of human parathyroid hormone (PTH(1-34)) on experimental osteopenia of rats induced by ovariectomy. Bone. Miner. 3:193-199.

13. Hock, J. M., J. R. Hummert, R. Boyce, J. Fonseca, and L. G. Raisz. 1989. Resorption is not essential for the stimulation of bone growth by $\mathrm{hPTH}(1-34)$ in rats in vivo. Bone Miner. 4:449-458.

14. Hock, J. M., J. Fonseca, M. Gunness-Hey, B. E. Kemp, and T. J. Martin 1989. Comparison of the anabolic effects of synthetic parathyroid hormone related protein 1-34 and PTH 1-34 on bone in rats. Endocrinology. 125:2022-2027.

15. Liu, C., and D. N. Kalu. 1990. Human parathyroid hormone (1-34) prevents bone loss and augments bone formation in sexually mature ovariectomized rats. J. Bone. Miner. Res. 5:973-982.

16. Tada, K., T. Yamanuro, H. Okumura, R. Kasai, and H. Takahashi. 1990 Restoration of axial and appendicular bone volumes by h-PTH (1-34) in parathyroidectomized and osteopenic rats. Bone. 11:163-169.

17. Mellish, R. W. E., V. Shen, R. Birchman, X. W. Meng, W. Horbert, D. W.
Dempster, and R. Lindsay. 1990. Quantitative analysis of trabecular bone in ovariectomized rats after intermittant administration of low dose human parathyroid hormone fragment (1-34) and 17-beta estradiol. In Proceedings of the Third International Symposium on Osteoporosis, Copenhagen. 224. (Abstr.)

18. Majeska, R. J., and G. A. Rodan. 1982. Alkaline phosphatase inhibition by parathyroid hormone and isoproterenol in a clonal rat osteosarcoma cell line. Possible mediation by cyclic AMP. Calcif. Tissue Int. 34:59-66.

19. Majeska, R. J., S. G. Rodan, and G. A. Rodan. 1980. Parathyroid hormone-responsive clonal cell lines from rat osteosarcoma. Endocrinology. 107:1494-1503.

20. Beresford, J. N., J. A. Gallagher, J. W. Poser, and R. G. G. Russell. 1984 Production of osteocalcin by human bone cells in vitro. Effects of $1,25(\mathrm{OH})_{2} \mathrm{D}_{3}$, $24,25(\mathrm{OH})_{2} \mathrm{D}_{3}$, parathyroid hormone and glucocorticoids. Metab. Bone Dis. Relat. Res. 5:229-234.

21. Beresford, J. N., J. A. Gallagher, J. W. Poser, and R. G. G. Russel. 1984. Production of osteocalcin by human bone cells in vitro: Effects of $1,25(\mathrm{OH})_{2} \mathrm{D}_{3}$, $24,25(\mathrm{OH})_{2} \mathrm{D}_{3}$, parathyroid hormone, and glucocorticoids. Metab. Bone Dis. Relat. Res. 5:229-234.

22. Beardsworth, L. J., D. R. Eyre, and I. R. Dickson. 1990. Changes with age in the urinary excretion of lysyl- and hydroxylysylpyridinoline, two new markers of bone collagen turnover. J. Bone Miner. Res. 5:671-676.

23. Robins, S. P., D. Black, C. R. Paterson, D. M. Reid, A. Duncan, and M. J. Seibel. 1991. Evaluation of urinary hydroxypyridinium crosslink measurements as resorption markers in metabolic bone diseases. Eur. J. Clin. Invest. 21:310315.

24. Uebelhart, D., E. Gineyts, M.-C. Chapuy, and P. D. Delmas. 1990. Urinary excretion of pyridinium crosslinks: a new marker of bone resorption in metabolic bone disease. Bone Miner. 8:87-96.

25. Riggs, B. L., and L. J. Melton. 1983. Evidence for two distinct syndromes of involutional osteoporosis. Am. J. Med. 75:899-901.

26. Gluer, C. C., P. Steiger, R. Selvidge, K. Ellieson-Kliefoth, C. Hayashi, and H. K. Genant. 1990. Comparative assessment of dual-photon absorptiometry and dual energy radiography. Radiology. 174:223-228.

27. Hodsman, A. B., J. H. Toogood, B. Jennings, L. Fraher, and J. C. Baskerville. 1991. Differential effects of inhaled budesonide and oral prednisolone on serum osteocalcin. J. Clin. Endocrinol. Metab. 72:530-540.

28. Cleary, J., and R. A. Saunders. 1974. A Simplified Procedure for the measurement of total hydroxyproline in urine. Clin. Chim. Acta. 57:217-223.

29. Hodgkinson, A., and T. Thompson. 1982. Measurement of the fasting urinary hydroxyproline: creatinine ratio in normal adults and its variation with age and sex. J. Clin. Pathol. 35:807-811.

30. Black, D., A. Duncan, and S. Robins. 1988. Quantitative analysis of the pyridinium cross-links in urine using ion-paired reverse phase high performance liquid chromatography. Anal. Biochem. 169:197-203.

31. Parfitt, A. M., M. K. Drezner, F. H. Glorieux, J. A. Kanis, H. Malluche, P. J. Meunier, S. M. Ott, and R. R. Recker. 1988. Bone histomorphometry: standardisation of nomenclature, symbols and units. J. Bone. Miner. Res. 2:595610 .

32. Crilly, R. G., D. H. Marshall, A. Horsman, B. E. C. Nordin, and R. Bouillon. 1981. $1 \alpha$-hydroxy $D_{3}$ with and without estrogen in the treatment of osteoporosis. In Osteoporosis-Recent Advances in Pathogenesis and Treatment. H. F. DeLuca, H. M. Frost, W. S. S. Jee, C. C. Johnston, and A. M. Parfitt, editors. University Park Press, Baltimore. 425-432.

33. Ljunghall, S., P. Gärdsell, O. Johnell, K. Larsson, E. Lindh, K. Obrant, and I. Sernbo. 1991. Synthetic human calcitonin in postmenopausal osteoporosis: a placebo-controlled, double-blind study. Calcif. Tissue Int. 49:17-19.

34. Fraher, L., A. B. Hodsman, K. Jonas, D. Saunders, C. I. Rose, J. E. Henderson, G. N. Hendy, and D. Goltzman. 1992. A comparison of the in vivo biochemical responses to exogenous parathyroid hormone (1-34) and parathyroid hormone-related peptide (1-34) in man. J. Clin. Endocrinol. Metab. 75:417423 .

35. Riggs, B. L., K. S. Tsai, and K. G. Mann. 1984. Evidence that serum Gla-protein is a measure of bone formation but not of bone resorption. Calcif. Tissue Int. 36:497-502.

36. Hauschka, P. V., J. B. Lian, D. E. C. Cole, and C. M. Gundberg. 1989. Osteocalcin and matrix Gla protein: vitamin K-dependent proteins in bone. Physiol. Rev. 69:990-1034.

37. Malluche, H. H., D. Sherman, W. Meyer, E. Ritz, A. W. Norman, and S. G. Massry. 1982. Effects of long-term infusion of physiologic doses of 1-34 PTH on bone. Am. J. Physiol. 242:F197-F201.

38. Podbesek, R., C. Edouard, P. J. Meunier, J. A. Parsons, J. Reeve, R. W. Stevenson, and J. M. Zanelli. 1991. Effects of two treatment regimes with synthetic human parathyroid hormone fragment on bone formation and the tissue balance of trabecular bone in greyhounds. Endocrinology. 112:1000-1006.

39. Price, P. A., J. G. Parthemore, and L. J. Deftos. 1980. New Biochemical Marker for Bone Metabolism. Measurement by radioimmunoassay of bone GLA protein in the plasma of normal subjects and patients with bone disease. J. Clin. Invest. 66:878-883.

40. Duda, R. J., J. F. O’Brien, J. A. Katzmann, J. M. Peterson, K. G. Mann, 
and B. L. Riggs. 1988. Concurrent assays of circulating bone Gla-protein and bone alkaline phosphatase: effects of sex, age, and metabolic bone disease. J. Clin. Endocrinol. Metab. 66:951-957.

41. Eriksen, E. F., L. Mosekilde, and F. Melsen. 1986. Trabecular bone remodeling and balance in primary hyperparthyroidism. Bone. 7:213-221.

42. Parisien, M., S. J. Silverberg, E. Shane, L. De la Cruz, R. Lindsay, J. P. Bilezikian, and D. W. Dempster. 1990. The histomorphometry of bone in primary hyperparathyroidism: preservation of cancellous bone structure. J. Clin. Endocrinol. Metab. 70:930-938.

43. Delmas, P. D. 1992. Biochemical markers of bone turnover: methodology and clinical use in osteoporosis. Am. J. Med. S5B:59S-63S.

44. Riis, B. J. 1991. Biochemical markers of bone turnover in diagnosis and assessment of therapy. Am. J. Med. S5B:64s-68s.

45. Eastell, R., P. D. Delmas, S. F. Hodgson, E. F. Eriksen, K. G. Mann, and B. L. Riggs. 1988. Bone formation rate in older normal women: concurrent assessment with bone histomorphometry, calcium kinetics, and biochemical markers. J. Clin. Endocrinol. Metab. 67:741-748.

46. Dandona, P., A. Coumar, D. S. Gill, J. Bell, and M. Thomas. 1988. Sodium fluoride stimulates osteocalcin in normal subjects. Clin. Endocrinol. (Oxf.). 29:437-441.

47. Simon, L. S., S. M. Krane, P. D. Wortman, I. M. Krane, and K. L. Kovitz. 1984. Serum levels of type 1 and 111 procollagen fragments in Paget's disease of bone. J. Clin. Endocrinol. Metab. 58:110-120.

48. Hassager, C., L. T. Jensen, J. S. Johansen, B. J. Riis, J. Melko, J. Podenphant, L. Risteli, C. Christiansen, and J. Risteli. 1991. The carboxy-terminal propeptide of type I procollagen in serum as a marker of bone formation: the effect of nandrolone decanoate and female sex hormones. Metab. Clin. Exp. 40:205-208.

49. Hasling, C., E. F. Eriksen, J. Melkko, L. Risteli, P. Charles, L. Mosekilde, and J. Risteli. 1991. Effects of a combined estrogen-gestagen regimen on serum levels of the carboxy-terminal propeptide of human type 1 procollagen in osteoporosis. J. Bone. Miner. Res. 6:1295-1300.

50. Eyre, D. R., I. R. Dickson, and K. Van Ness. 1988. Collagen cross-linking in human bone and articular cartilage: age-related changes in the content of mature hydroxypyridinium residues. Biochem. J. 252:495-500.

51. Uebelhart, D., A. Schlemmer, J. S. Johansen, E. Gineyts, C. Christiansen, and P. D. Delmas. 1991. Effect of menopause and hormone replacement therapy on the urinary excretion of pyridinium cross-links. J. Clin. Endocrinol. Metab. 72:367-373.

52. Delmas, P. D., A. Schlemmer, E. Gineyts, B. Riis, and C. Christiansen. 1991. Urinary excretion of pyridinoline crosslinks correlates with bone turnover measured on iliac crest biopsy in patients with vertebral osteoporosis. J. Bone. Miner. Res. 6:639-644.

53. Dahl, E., K. P. Nordal, J. Halse, and A. Attramadal. 1988. Histomorphometric analysis of normal bone from the iliac crest of Norwegian subjects. Bone. Miner. 3:369-377.

54. Eriksen, E. F., S. F. Hodgson, R. Eastell, S. Cedel, W. M. O'Fallon, and B. L. Riggs. 1990. Cancellous bone remodeling in type I (postmenopausal) osteoporosis: quantitative assessment of rates of formation, resorption, and bone loss at tissue and cellular levels. J. Bone. Miner. Res. 5:311-319. 